\title{
IMPORTANCE OF METEOROLOGICAL FACTORS TO THE INCIDENCE OF POLIOMYELITIS
}

\author{
BY \\ E. N. LAWRENCE \\ Meteorological Office, London
}

The following note describes briefly the present state of research into the influence of meteorological factors on poliomyelitis incidence. Recent work concerns primarily the effects of dry-bulb temperature, relative humidity, and vapour pressure; other meteorological factors, including rainfall, are also discussed. Results are fairly consistent, though this may not be at first apparent.

Three recent investigations are based on mean values of dry-bulb temperature and vapour pressure for four stations: London Airport, Plymouth, Tynemouth, and Manchester. Using weekly values for the years 1947-1952 inclusive, Bradley and Richmond (1953) concluded that there was a tendency for lower average seasonal temperature/vapour pressure to occur with the lowest incidences of poliomyelitis. From a study of these temperature data, Lawrence (1956) showed that incidence was highly correlated with "accumulated" temperature above a threshold temperature. Using monthly averages for the years 1947-1956 inclusive, Spicer (1959) obtained strong positive correlations with temperature and negative correlations with relative humidity, but "found that vapour pressure was not related to the incidence of poliomyelitis". However, Spicer states that his analysis does not exclude the possibility that other meteorological variables, closely related to temperature and relative humidity, may be involved.

It can be shown from the above-mentioned data (or other British data) that temperature correlates highly with vapour pressure. Thus, the possibility of high vapour pressure being associated with high poliomyelitis incidence cannot be excluded. Actually, Spicer has shown that temperature and relative humidity account for much of the variation of poliomyelitis incidence, and he implies that the inclusion of vapour pressure does little or nothing to reduce the residual variance. These findings do not indicate that temperature and vapour pressure together would not correlate highly with poliomyelitis incidence, relative humidity adding little more to the picture; but, presumably (using the method employed by Spicer), this correlation would not be so high as for temperature and relative humidity. It would be helpful if fuller details of the statistical analysis were available.

The statement by Spicer that Lawrence (1956) "quotes some unpublished studies in the Meteorological Office which demonstrated little correlation between poliomyelitis incidence and temperature or ${ }^{\gtrless}$ relative humidity" is misleading. The studies quoter $\bar{\varphi}$ mainly demonstrate a correlation with temperature ? relative humidity is not discussed. Indeed, the high "polio-temperature correlation" obtained (Lawrence 1956) would suggest that poliomyelitis incidence correlates significantly with vapour pressure (positively) and with relative humidity (negatively); and such possibilities are suggested in this and a later paper (Lawrence, 1958), which states that the temperature function employed is indicative of evaporation or atmospheric "drying-power".

If, as suggested by Spicer (1959), atmospheric "drying-power" is related to the incidence of polio- $\frac{\rho}{S}$ myelitis, then it might be useful to employ a function such as

$$
E=0 \cdot 35(1+u / 100)\left(e_{s}-e\right) \mathrm{mm} . / \mathrm{day}
$$
(Penman, 1948)

where $E=$ a measure of the potential evaporation $u=$ mean air velocity at $2 \mathrm{~m}$. height (ml. per day)

$e=$ atmospheric vapour pressure (mm. Hg.)

$e_{s}=$ atmospheric saturation vapour pressure (mm. Hg.)

or, at least, in the absence of wind data, $\left(e_{s}-e\right)$, the $N$ saturation deficit.

$$
\begin{aligned}
e_{s}-e= & e_{s}(1-r), \text { where } r \text { is the relative humidity } \\
= & (1-r)(a+b \mathrm{~T}), \text { for relatively small tem- } \\
& \text { perature }(\mathrm{T}) \text { range }
\end{aligned}
$$

which is essentially of the form

$\alpha-\beta r+\gamma \mathrm{T}$, where $\beta$ and $\gamma$ are positive constants. 
Thus, on the assumption that "drying-power" is the important factor, then $T$ (correlating positively) and $r$ (correlating negatively) would seem to be more important than vapour pressure.

The statistical procedures of Paragraphs 2 and 3 above are further weakened by the following:

(i) Averaging data for different places with widely dissimilar local meteorological characteristics, as for example, London Airport and Plymouth;

(ii) Using monthly averages, which mask important meteorological variations, the effect of which on "polio" incidence may be further complicated by such non-meteorological influences as ice cream consumption and bathing (Spicer, 1959; Lawrence, 1957);

(iii) The rather limited range of meteorological factors in Britain (especially vapour pressure) which tends to conceal any extreme thresholds beyond which conditions may be unfavourable to the virus, such as a high temperature.

The effect of (iii) might be overcome by examining the problem in different climatic regimes in America and Australia, for example. The effect of (ii) is particularly confusing in view of the "incubation period" and delay in notification.

Armstrong (1952) gives an "incubation period" of 7 to 14 days, Martini (1956) a lag of about 2 weeks, and Bradley and Richmond (1953) a lag of 3 weeks. Spicer considers the effects of the previous month's data, but the amount of lag may be shown more clearly by using weekly values.

The Table gives correlation coefficients between temperature/vapour pressure and poliomyelitis incidence $0,1,2,3, \ldots 8$ weeks later.

The Table was obtained thus:

(i) By using weekly values of temperature and vapour pressure for weeks 18 to 42 inclusive (where week 1 is January 1 to 7 , etc.), in order to calculate correlations for each of the years 1947 to 1956 (total poliomyelitis incidence) and 1950 to 1956 (paralytic poliomyelitis incidence);

(ii) By averaging these annual values. Peak values (printed in bold type in the Table) of these correlation coefficients occur mainly around the column for "three weeks' lag".

When considering the effects of dry weather, it is important to distinguish between absence of rainfall and low relative humidity or relatively low vapour pressure. High vapour pressure and high rainfall, though associated meteorologically, could have
TABLE

CORRELATION COEFFICIENTS

(peak values in bold figures)

\begin{tabular}{|c|c|c|c|c|c|c|c|c|c|}
\hline \multirow[t]{2}{*}{ Factors } & \multicolumn{9}{|c|}{$\begin{array}{l}\text { Poliomyelitis incidence refers to the following } \\
\text { number of weeks after the corresponding } \\
\text { meteorological data: }\end{array}$} \\
\hline & 0 & 1 & 2 & 3 & 4 & 5 & 6 & 7 & 8 \\
\hline $\begin{array}{l}\text { Total poliomyelitis } \\
\text { incidence and tem- } \\
\text { perature .. } \\
\text { Total poliomyelitis } \\
\text { incidence and va- } \\
\text { pour pressure . } \\
\text { Paralytic poliomye- } \\
\text { litis incidence and } \\
\text { temperature } \\
\text { Paralytic poliomye- } \\
\text { litis incidence and } \\
\text { vapour pressure }\end{array}$ & $\cdot 39$ & .49 & $\cdot 55$ & .61 & $\cdot 60$ & .61 & $\cdot 58$ & $\cdot 39$ & $\begin{array}{l}.42 \\
.30\end{array}$ \\
\hline
\end{tabular}

opposite effects on the incidence of the disease: atmospheric washing of airborne infection by rain may counteract the effect of high humidity (see next paragraph). Thus, without considering the effect of rainfall, it is perhaps dangerous to formulate conclusions regarding other "humidity" or "wetness" parameters.

The association of vapour pressure or closely allied factors with poliomyelitis is claimed by a number of investigators. Martini (1956) states that infection is associated with high vapour pressure; Seemann (1951), Scherer (1952), and Hahn (1952) associate poliomyelitis with "unstable upglide phenomena", which (according to Martini, 1956) may be compared with warm fronts; Krey (1956) and Becker (1956) support the latter results; Wada (1952) relates maximum incidence with preceding high relative humidity (and low rainfall); Dreisrios (1956) associates poliomyelitis with "cold damp" conditions.

The rate of loss of water from the human respiratory system may be written in the form:

$$
E=A(B-e) / \mathrm{T}
$$

where $E=$ water loss

$\boldsymbol{e}=$ atmospheric vapour pressure

$\mathrm{T}=$ atmospheric temperature in degrees absolute $A$ is proportional to the rate of respiration

$B$ is dependent upon the temperature and humidity of expired air.

If expired air has a temperature of $98^{\circ} \mathrm{F}$. and 100 per cent. humidity, $B=61.7$ (mb.), a value which is normally far in excess of $e$ (Tunnell, 1958). Summer conditions of high $e$ and high $T$ tend to give a low $E$. If high $T$ is associated with high poliomyelitis incidence, there is the suggestion that the latter is associated with low $E$; low $E$ could be caused also by high $e$, as well as by high $\mathrm{T}$. This lends support to 
the medical aspects of Armstrong's hypothesis (Armstrong, 1950, 1951, 1952; Armstrong, Dixon, and Chadwick, 1952) and to the possible significance of high $e$.

In a recent paper, Hemmes, Winkler, and Kool (1960) describe some laboratory experiments with aerosols, and conclude that relative humidity, indoors, is an important environmental factor contributing to the seasonal fluctuations of the morbidity of poliomyelitis: their Figure 1 shows that the death rate of the virus is diminished at higher relative humidities. However, the normal range of indoor temperature is considerably restricted, and possibly even virtually constant, and indoor relative humidity may well be governed by the outdoor ambient atmospheric vapour pressure. Thus high outdoor vapour pressure could be closely associated with high indoor relative humidity, and both these factors could be related to high incidence of poliomyelitis.

To summarize-progress is necessarily limited for the following reasons:

(a) The inherent difficulties of obtaining appropriate micrometeorological data as distinct from standard meteorological data;

(b) The variation of meteorological conditions over short periods;

(c) The close association of meteorological and non-meteorological variables having different or opposite effects on the incidence of poliomyelitis.

More success may be achieved from further investigations using the method employed by Spicer, but using data for (i) meteorologically more homogenous areas, (ii) shorter unit periods than a month and (iii) various climatic regimes outside Britain. Also, more attention should be given to the possible effects of high outdoor vapour pressure, which, judging from the work described above, would appear to be more important than low outdoor relative humidity in causing a high incidence of poliomyelitis. Finally, in any such investigations, some allowance might usefully be made for the possible effects of rainfall.

However, with data further complicated by vaccination (since 1957), it is considered that a stage has been reached where more progress in poliomyelitis research would probably be made by meteorologically-controlled biological experiments.

This note is published by permission of the DirectorGeneral, Meteorological Office.

\section{REFERENCES}

Armstrong, C. (1950). Amer. J. publ. Hlth, 40, 1296. (1951). Ibid., 41, 231.

(1952). Proc. nat. Acad. Sci., 38, 613.

- Dixon, J. P., and Chadwick, W. L. (1952). Amer.J. publ. Hlth, 42, 1246.

Becker, F. (1956). Med.-met. Hefte (Hamburg), 11, 120. (Dissertation extr.).

Bradley, W. H., and Richmond, A. E. (1953). Monthly Bull. Minist. Hlth. Lab. Serv., 12, 2.

Dreisrios, D. (1956). Med.-met. Hefte (Hamburg), 11, 120. (Dissertation extr.).

Hahn, W. (1952). Dissertation, Frankfurt. Med.-met. Hefte (Hamburg), 11, 116.

Hemmes, J. H., Winkler, K. C., and Kool, S. M. (1960) Nature (Lond.), 188, 430.

Krey, W. (1956). Med.-met. Hefte (Hamburg), 11, 118. Lawrence, E. N. (1956). Met. Mag. (Lond.), 85, 164. (1957). Ibid., 86, 374.

- (1958). Proc. roy. Soc. Med., 51, 261.

Martini, R. (1956). Med.-met. Hefte (Hamburg), 11, 111 Penman, H. L. (1948). Proc. roy. Soc., Ser. A., 193, 120.

Seemann, K. (1951). Dissertation, Frankfurt. Med.-met. Hefte (Hamburg), 11, 116.

Scherer, T. (1952). Ibid., 11, 116.

Spicer, C. C. (1959). Brit. J. prev. soc. Med., 13, 139.

Tunnell, G. A. (1958). Geophys. Mem. (Lond.), 12, No. 100.

Wada, H. (1952). Geophys. Mag. (Tokyo), 23, 55. 